\title{
GESTÃO PEDAGÓGICA, O CURRÍCULO E AS TECNOLOGIAS
}

\section{PEDAGOGICAL MANAGEMENT, CURRICULUM AND TECHNOLOGIES}

\author{
Fernando José de Almeida1', Maria da Graça Moreira da Silva², Lucila Lerro Rupp ${ }^{3}$
}

\begin{abstract}
RESUMO
Este artigo reflete sobre a gestão pedagógica para a educação de qualidade social. Para tal, versa sobre a articulação entre a gestão pedagógica, o currículo e as tecnologias. Com abordagem qualitativa, apresenta um estudo de caso por meio da análise dos documentos relacionados à implantação do Sistema de Gestão Pedagógica, vendo neles a busca de uma forma democrática de fazer a gestão pedagógica de amplo espectro na direção de uma educação de qualidade social. Retoma o conceito de qualidade social. Dentre as considerações, destaca-se que um sistema de gestão pedagógica deve escapar da gestão para o controle e centrar-se no processo de elaboração das funcionalidades por e com os educadores, enfatizando seu processo de construção e a reflexão sobre a qualidade do fazer pedagógico. Destaca-se, também, o contexto institucional mais amplo de sua criação, o de um compromisso com um projeto curricular. As evidências mostraram a força do potencial formativo para os gestores e docentes da rede de ensino, seja na ampliação das competências dos docentes para a reflexão sobre o fazer pedagógico, analisar os processos cognitivos dos alunos e das classes, seja para os gestores enquanto desenhistas de processos democráticos educacionais.
\end{abstract}

PALAVRAS-CHAVE: Currículo, Tecnologia da informação e comunicação, Gestão pedagógica da escola, Gestão democrática da escola

\section{ABSTRACT}

This article reflects on the pedagogical management for social quality education. To this end, it deals with the articula-

\footnotetext{
1 Possui graduação em Filosofia e Pedagogia pela Faculdade Nossa Senhora Medianeira (1970), com Mestrado e Doutorado em Filosofia da Educação pela Pontifícia Universidade Católica de São Paulo (1977 e 1984), onde leciona, como professor titular, no Programa de Pós-graduação em Educação: Currículo. Fez seu pós-doutorado em convênio CNPQ/CNRS, em Lyon - França, no IRPEACS, em 1986-1987. Suas pesquisas se desenvolveram na área de Uso das Tecnologias da Informação e Comunicação para aprendizagem e políticas públicas. Foi Vice-Reitor Acadêmico da PUC (1992-1995). Secretário Municipal de Educação da Cidade de São Paulo (2001-2002). Participou do Programa de formação de Mestres e Doutores em Educação em Moçambique entre 1999-2006. Vice-Presidente da Fundação Padre Anchieta - Rádios e TV Educativas SP e Diretor de Educação (2007-2013 e 2019 - 2020). Diretor de avaliação, currículo e formação - COPED - da Secretaria de Educação Municipal da Cidade de São Paulo. Foi diretor nacional do SESC nas áreas de Educação e Cultura (2017). É membro do conselho do Museu da Língua Portuguesa e do Museu do Futebol e do São Paulo: Companhia de Dança. É membro honorário da Academia Paulista de Educação. Tem experiência na área de Educação, com ênfase em tecnologia da educação, atuando principalmente nos seguintes temas: educação, currículo, ensino-aprendizagem, informática e formação de professores.

${ }^{2}$ Maria da Graça Moreira da Silva concluiu o doutorado em Educação (Currículo) pela Pontifícia Universidade Católica de São Paulo em 2004. Atualmente é docente do Departamento de Computação e do Programa de Pós-graduação em Educação: Currículo da Pontifícia Universidade Católica de São Paulo. Consultora na implantação de projetos educacionais e sociais em secretarias de educação, secretarias da saúde, instituições de ensino, ONG e empresas. Experiência na gestão de projetos em larga escala, na formação de recursos humanos para inovação, e-learning, EaD e tecnologias. Participou de diversos projetos internacionais e nacionais junto ao MEC, UNDIME, PRADIME, UNDP e em outras instituições governamentais e não governamentais.

${ }^{3}$ Possui graduação em Jornalismo pela Faculdade Cásper Líbero, especialização em Jornalismo Social pela PUC-SP. Na mesma instituição, cursou mestrado no programa Educação: Currículo, no qual atualmente faz doutorado. Tem experiência em reportagem e elaboração de roteiros de documentários, vídeos educacionais e de divulgação científica. Foi repórter da série SP Pesquisa programa de divulgação científica da Fapesp veiculado na TV Cultura. Roteirista de objetos audiovisuais da editora FTD voltados ao Programa Nacional do Livro Didático e roteirista da série que integrou o curso de Pedagogia da Univesp-TV.
} 
tion between pedagogical management, curriculum and technologies. With a qualitative approach, it presents a case study through the analysis of documents related to the implementation of the Pedagogical Management System, seeing in them the search for a democratic way of doing pedagogical management of a broad spectrum in the direction of a social quality education. Resumes the concept of social quality. Among the considerations, it is highlighted that a pedagogical management system must escape from management for control and focus on the process of elaborating the functionalities by and with educators, emphasizing its construction process and the reflection on the quality of pedagogical practice. It also stands out the wider institutional context of its creation, that of a commitment to a curricular project. The evidence showed the strength of the training potential for managers and teachers in the education network, whether in expanding the skills of teachers to reflect on pedagogical practice, analyze the cognitive processes of students and classes, or for managers as designers of democratic educational processes.

KEYWORDS: Curriculum. Information and Communication Technologies. Educational management. Democratization of education 


\section{INTRODUÇÃO}

A educação escolar pública brasileira está em tempos de descobertas, descréditos, esperanças, inseguranças, falta de programas teóricos, de currículo claro, de investimentos orgânicos: de autonomia e de senso crítico. Inexistem, de fato, estudos estratégicos sobre sua missão, sua finalidade e seu local social. Todos opinam sobre ela. O senso comum impera, travestido de ciência ou buscando uma espécie de "finlandização" do sistema escolar, como interpretação mais óbvia do nosso baixo desempenho em exames internacionais.

Sabe-se, mas é mantido nas sombras da memória, que foi construído um Plano Nacional de Educação (PNE) pelo Ministério da Educação (Brasil, 2014), com metas claras, conceitos articulados e indicação de investimentos. Um documento que nos impede de dizer que não existem projetos para a Educação Brasileira. Além disso, a criação da Base Nacional Comum Curricular, promulgada no final de 2017, também ilumina conceitos e define rumos.

A alegada falta de norte para a educação se reflete no emprego das tecnologias digitais da informação e comunicação (TDIC) nas escolas, tão patente no ano de 2020, em que as diferenças no acesso e uso evidenciaram a questão da inclusão/exclusão educacional e social. Entretanto, o foco desta reflexão é voltado para a gestão pedagógica dos professores em uma rede de ensino mediatizada por um sistema tecnológico.

Este artigo traz as reflexões filosóficas, políticas e pedagógicas para abrir o diálogo articulando, assim, a gestão pedagógica, o currículo e as tecnologias, dando precisão ao conceito de qualidade social da educação, sem o qual todas as soluções caem em armadilhas simplificadoras de soluções para as questões postas. As questões iniciais que instigaram a pesquisa são: como a gestão pedagógica pode trazer qualidade social da escola? Em que ela pode mediar os processos de ensino envolvendo mais os professores e alunos em seu protagonismo e as famílias em suas específicas responsabilidades? Quais aspectos formativos que daí resultam?

Este artigo considera que a qualidade social da educação decorre de diversos fatores combinados, dentre os quais a apropriação crítica das tecnologias; a formação de docentes; a formação de alunos; a gestão; a inserção à linguagem que flui nas redes conectadas; a produção e distribuição de conhecimentos; a construção de novas sociabilidades, identidades, valores, relações humanas; e a participação social. Isso tudo à luz do compromisso social da escola com o conhecimento e a formação da cidadania.

A aproximação da gestão pedagógica, o currículo e as tecnologias são aqui analisados a partir da reforma curricular da Secretaria Municipal de Educação de São Paulo [SME] (2013-2015) e, mais especificamente, o caso do sistema tecnológico para seu monitoramento, o Sistema de Gestão Pedagógica (SGP). Este artigo relata/e reflete sobre o caso do SGP no que iniciou seu processo de concepção em 2013, sua implantação em 2014 e sua nova versão em 2020. Iniciado em 2013 na Secretaria Municipal de Educação de São Paulo, o SGP já se tornou objeto de investigação de onde se originaram, também, pesquisas acadêmicas. Dele destacam-se o processo de construção com a rede municipal de educação e seus agentes do ambiente de gestão pedagógica em que registro de dados, publicações reflexivas e formativas sobre o tema, assim como alguns dos percalços de sua implantação e sua nova versão, revelam-se e apontam para novas tessituras do cotidiano, do ensino, da aprendizagem e da relação com as famílias.

Como se desenham os instrumentos políticos e técnicos de uma gestão pedagógica com qualidade social? Esta é a questão problema que norteia a reflexão do caso em tela.

\section{SUBSUNÇORES}

\section{Gestão pedagógica para a educação de qualidade social}

A promoção de uma educação pública com qualidade social é um dos desafios colocados ao Brasil e encontra-se em tela, destacadamente, nestas primeiras décadas do século XXI. Este debate congrega e mobiliza os distintos segmentos da sociedade balizado em diversos olhares, como nas experiências exitosas do Brasil e exterior, nos avanços históricos da política educacional brasileira estreado na década de 1990, nas análises dos dados estatísticos educacionais decorrentes das avaliações de larga escala, nos dados sociométricos e de índices comparativos 
da educação mundial.

O conceito de qualidade social possui múltiplas vertentes e especificações na história da educação. Trata-se de um conceito que se constrói e se ressignifica de acordo com determinadas concepções que se tornam hegemônicas numa ou noutra época.

Para que escapemos da armadilha de estarmos atrelados ao conceito de "qualidade" em voga, é fundamental que definamos seus atributos. Qualidade do ponto de vista filosófico é um conceito genérico. Tudo tem a qualitas, a qualis, que explicita o que a coisa é. A questão que se pontua aqui é saber qual é a adjetivação da qualidade. Que tipo de qualidade? Qualidade para quem? A qualidade pode ser boa ou má, bonita ou feia, perversa ou benéfica. Ninguém duvida que as perspectivas sociais nazistas tivessem uma forte qualidade, tão apelativa que milhões de pessoas a ela aderiram na Europa dos anos 1920 a 1940, mesmo depois dos horrores da Primeira Grande Guerra. Era uma qualidade para uma raça, para um grupo social, para uma nação, para um modelo de poder. Era uma qualidade contra grupos; qualidade que se valia da força para impor um modelo de economia de justiça de liberdade, de beleza que de forma violenta e arbitrária se opunha à diversidade, à tolerância, à paz etc.

O problema que se coloca à educação brasileira é definir o conceito "qualitativo" de qualidade da educação: o termo qualidade social já indica que o resultado pretendido é a qualidade que garante a inclusão de todos com a permanência, a qualidade da aprendizagem e a oportunidade para todos. A qualidade social é evidenciada com um olhar para a escola como o local privilegiado para o desenvolvimento da aprendizagem e destacadamente, da formação de valores sociais, éticos e de cidadania: valores mediados pelo conhecimento. Portanto, o conceito de qualidade que norteia este artigo não se restringe à qualidade enquanto métrica de resultados, nem se refere ao sucesso dos estudantes traduzidos por índices de desempenho em grandes sistemas avaliativos. Também não se refere à quantidade ou à modernidade dos insumos necessários para apoiar a educação. Todas estas variáveis são necessárias à qualidade social, mas não a esgotam.

Casali (2014) aponta algumas condições para a qualidade social da educação: a infraestrutura física adequada; o projeto pedagógico construído no coletivo e com a participação da comunidade; a carreira docente efetiva; processos de avaliação transparentes dos profissionais da educação e a vivência de uma gestão democrática.

No interior da escola, a qualidade social está vinculada ao movimento do currículo que se desdobra em experiências de valor nas diferentes dimensões para todos; à gestão democrática e participativa; ao efetivo envolvimento e corresponsabilidade das famílias na formação; à valorização das identidades e dos progressos dos educandos.

Fatores, subjetivos e intersubjetivos, exteriores e interiores estão imbricados na escola de qualidade social. Como fatores exteriores:

\footnotetext{
... um conjunto de elementos e dimensões socioeconômicas e culturais que circundam o modo de viver e as expectativas das famílias e de estudantes em relação à educação; que busca compreender as políticas governamentais, os projetos sociais e ambientais em seu sentido político, voltados para o bem comum; que luta por financiamento adequado, pelo reconhecimento social e valorização dos trabalhadores em educação; que transforma todos os espaços físicos em lugar de aprendizagens significativas e de vivências efetivamente democráticas. (SILVA, 2009, p. 225)
}

No interior da escola, a qualidade social está vinculada ao movimento do currículo que se desdobra em experiências de valor nas diferentes dimensões para todos, à gestão democrática e participativa; ao efetivo envolvimento e corresponsabilidade das famílias na formação; a valorização das identidades, dos progressos dos educandos.

O grande desafio é "articular formação, avaliação, e Gestão Pedagógica em um movimento curricular que realize a relação entre teoria e prática..." (SÃO PAULO, 2014, p.12). Frente a este desafio, o foco deste artigo será direcionado à gestão pedagógica como um dos instrumentos necessários (mas não suficientes) para a educação de qualidade social, sem desconhecer ou desconsiderar as demais dimensões, mas iluminando como sua integração com as tecnologias e currículo suscitam a visão de contornos originais do cotidiano e a construção colaborativa e do empoderamento e da memória dos atores da escola. 
A promoção de uma educação pública com qualidade social não está desarticulada dos desafios contemporâneos. Assim, as tecnologias são entendidas, também, como instrumentos da educação essenciais para a construção da qualidade social do trabalho escolar.

\section{Tecnologias e gestão para a educação de qualidade social}

Uma primeira providência a ser tomada para o início deste diálogo é desconstruir o equívoco oriundo do senso comum: as tecnologias per se não conseguem promover mudanças na educação. Não foram feitas para isso. Não faz parte de sua essência (quiditas), mas da sua qualidade, de sua qualitas. As mudanças na educação são complexas, multidimensionais e demandadas por valores e indicadores oriundos de projetos políticos e educacionais de uma nação. As inovações curriculares, igualmente, são consequentes de processos de debates e disputa em diversas esferas da sociedade e construídas no coletivo por meio de políticas educacionais coerentes com os saberes construídos no chão da escola. Envolve também um profundo debate da e na escola. Daí deve emergir o entendimento do movimento permanente de discussão da representação social na cultura e na política.

Mudanças educacionais sugerem políticas públicas que envolvam ações de amplitudes maiores, com olhares mais profundos à cultura local e global, à escola e à comunidade. A introdução de tecnologias na escola não deve se limitar ou se absolutizar a ponto de ofuscar o seu papel como processo social que reconfigura as características identitárias dos agentes educacionais (ZUIN, 2010).

As tecnologias só cumprem papeis significativos para a aprendizagem quando dirigidas por projetos político-pedagógicos de maior envergadura, determinados por estruturas curriculares sólidas. Se falarmos de qualidade social da educação, as tecnologias se atrelam necessariamente ao programa curricular com a mesma tendência político-pedagógica. A sua harmonização ou inserção essencial com o currículo dá-lhe inúmeras perspectivas de criação de uma cultura digital sólida para a escola, para o sistema, para as famílias e para os alunos. A sua capilaridade nas ações de planejamento e de documentação para a difusão de resultados pela criação de ambiente de diálogo entre os atores faz a diferença na construção de uma educação de qualidade social, pois mantém vivas as documentações, os trajetos pedagógicos, os domínios de responsabilidades e os atores em evidência.

Como afirma Vieira Pinto (2005, p.735)

"A técnica, por essência, significa um existencial do homem, e consequentemente nunca lhe poderia ser antagônica, visto dele não se destacar, senão quando manipulada por outro homem que a rigor se veste dela para atacar e sacrificar um semelhante...".

O senso comum, portanto, traz o olhar, a análise e a interpretação fragmentados e acríticos e não revelam o pensamento científico ou reconhecem o papel diferenciado e contraditório da cultura digital, seus elementos constituintes e suas relações com a educação.

A integração das tecnologias à educação, conforme Silva (2011), demanda o reconhecimento da capacidade autora da própria escola, compreendida na perspectiva de sujeito, criadora de cultura, que vive cercada por tecnologias que convergem para permitir, além da comunicação e da navegação, que professores e alunos aprendam e sejam produtores, difusores e compartilhadores da informação: autores na cultura. O que implica que a escola se enxergue como sujeito de cultura e participe desta cultura. Na cultura digital a autoria, como em outras dimensões da educação, também é precedida pela leitura crítica do mundo digital, mas "A leitura deste mundo não pode ser feita com os mesmos instrumentos de mundos passados" (ALMEIDA, 2009, p. 30). Portanto, a leitura do mundo contemporâneo envolve a apropriação e uso de tecnologias, por suas novas linguagens e seus meandros percorridos em redes.

Um sistema de gestão pedagógica é uma plataforma tecnológica que, usualmente, possui funcionalidades de controle, como dados cadastrais de alunos, professores, matriz curricular, notas e faltas, turmas, disciplinas; histórico escolar e outras funcionalidades que se relacionam com a gestão administrativa de uma escola ou rede de 
escolas. Neste artigo nos referimos a um sistema que caminha para além da gestão administrativa, mas um sistema voltado ao monitoramento da educação, essencial para a gestão do currículo e, em especial do PPP. Atividade considerada burocrática e inútil, até mesmo centralizadora ou autoritária para professores e para gestores, a gestão acaba sendo relegada e suas práticas distorcidas.

A gestão pedagógica, usualmente associada ao papel da coordenação pedagógica, neste artigo é entendida de forma alargada, englobando a prática do professor e dos demais agentes escolares. Não se limita não à gestão da sala de aula, mas de todo o processo de ensinar a aprender, sem fragmentá-lo ou centrá-lo na figura dos gestores escolares. A gestão democrática e participativa deve contar com a voz de todos e nos espaços-tempos que, no conjunto, contribuem com a vida mesma da escola.

A gestão do cotidiano vivido pela escola se alinha ao registro e, mais propriamente, ao tripé: planejamento, registro e avaliação. Ao fazer o registro, o educador, segundo Freire (1983), realiza a reflexão diária e contínua sobre sua prática. "através da reflexão diária o professor avalia e planeja sua prática. Ele também é um importante documento, onde o vivido é registrado... Nesse sentido, educador e educando, juntos, repensam sua prática" (p. 77). Assim, o exercício do registro e sua recuperação e análise abre espaços para a "reflexão sobre o seu fazer, para avaliar o caminho pedagógico planejado, redefinindo passos ou reafirmando o caminhar" (OSTETTO, 2018, n.p.). Segundo a autora, ao registrar e refletir sobre sua prática, os educadores "apropriam-se de suas histórias, ensaiam autoria", tecem sua memória da experiência e se relacionam com a formação continuada ou autoformação. Para tal, é necessário "formar" o olhar e a escuta, colaborativamente.

\section{Trajetória metodológica - o caso do Sistema de Gestão Pedagógica-SGP}

Com abordagem qualitativa, este trabalho advém da análise de conteúdo dos documentos públicos disponíveis no sítio da Secretaria Municipal de Educação de São Paulo, a saber:

- Mais Educação São Paulo: programa de reorganização curricular e administrativa, ampliação e fortalecimento da Rede Municipal de Ensino de São Paulo. (SÃO PAULO, 2013)

- Notas técnicas sobre o documento de referência do programa de reorganização curricular e administrativa, ampliação e fortalecimento da rede municipal de ensino de São Paulo. (SÃO PAULO. 2013b)

- Regimento educacional das unidades da rede municipal de ensino. Portaria 5941/13 - SME, de 15 de outubro de 2013. (SÃO PAULO, 2013c).

- Programa mais educação São Paulo. Subsídios para implantação. (SÃO PAULO, 2014)

- Programa Mais Educação São Paulo. Subsídios para implantação: avaliação para a aprendizagem e SGP. (SÃO PAULO, 2014b).

- Revista Magistério (3). O aluno. (São Paulo, 2014c)

- Revista Magistério (4). Avaliação como Direito do Aluno. (SÃO PAULO, 2015)

- Secretaria Municipal de Educação. Portal. (SÃO PAULO, 2015b, 2020)

- Novo SGP: Manual do Novo Sistema de Gestão Pedagógica. (SÃO PAULO, 2020)

Os documentos foram analisados (análise de conteúdo) e os dados coletados organizados de forma a contemplar as seguintes categorias que nortearam o trabalho: "Gestão das informações da educação", "Diagnóstico", "Planejamento, avaliação e acompanhamento da trajetória dos alunos", "Gestão do Conselho de Classe", "Espaços autorais para os alunos"; "Boletim online e transparência"; e "Desafios". Esses componentes interagem entre si e representam as ações do planejar ao compartilhar os dados educacionais.

A seguir são apresentados e analisados os dados coletados.

\section{ANÁLISE DOS DADOS COLETADOS Origem do Sistema de Gestão Pedagógica-SGP}

A Rede propõe em 2013, juntamente com sua comunidade e com a escuta pública, o Programa Mais Educação 
São Paulo: Programa de Reorganização Curricular e Administrativa, Ampliação e Fortalecimento da Rede Municipal de Ensino de São Paulo (Rede), que previu a implantação de diversas ações com vistas à melhoria da qualidade social da educação. Uma reforma curricular desta monta, envolvendo, segundo o portal da Secretaria Municipal de Educação de São Paulo (2015b), 1.500 escolas, 84.000 professores e gestores e aproximadamente 1.000 .000 de alunos, não pode ser implantada responsavelmente sem um amplo e rigoroso planejamento, sem um sistema de acompanhamento e de gestão que dialogue com as práticas pedagógicas que se desenvolvem no interior da Rede. Não se trata de construir e implantar um sistema de controle e geração de resultados imediatos ou um panóptico eletrônico para a vigília ou punição: trata-se de desenvolver um desenho colaborativo para acompanhamento, ajuste de rumos e estímulo a investimentos em ações que vislumbrem acertos e oportunidades.

Um sistema de gestão com essas características deve ser elaborado num processo sistemático e gradativo de consultas a gestores, supervisores de educação, coordenadores pedagógicos e rede de professores. O sistema supõe um processo de diálogo e formação. O objeto do consensualmente e da construção coletiva partiu do tema de avaliação para a aprendizagem e foi se espraiando para os fundamentos da gestão educacional. Capturar o andamento e avaliar o todo de uma reforma curricular que supunha implantar um currículo, reconstruir a prática à luz dessa proposta; acompanhar os resultados foi tarefa que se consubstanciou num sistema tecnológico de gestão pedagógica.

Segundo a portaria 1.224/14 (SÃO PAULO, 2014b, p. 29) que institui o SGP na Secretaria Municipal de Educação, esse sistema, integrado ao Sistema Escola online - EOL, em uso para gestão educacional, tem por objetivo "organizar e potencializar o acompanhamento pedagógico dos estudantes pelos pais/responsáveis, professores, gestores das Unidades Educacionais - UEs, Diretorias Regionais de Educação - DREs e pela própria Secretaria Municipal de Educação."

De tal modo, o SGP foi desenhado como um sistema tecnológico com o objetivo de potencializar a gestão pedagógica por meio da escrituração e documentação qualificada da prática pedagógica das escolas, articulando o fazer pedagógico do interior da sala de aula e da escola a um processo dinâmico e contínuo de diagnóstico, planejamento, ação, documentação, avaliação, reflexão para a ação em prol do acompanhamento cuidadoso do projeto político-pedagógico, dos planos de ensino, da trajetória dos alunos para o (re)planejamento e a (re)avaliação constante da "vida mesma da escola".

O processo de ação-reflexão-ação necessário é fomentado pela gestão das escolas, pelo planejamento, registro, recuperação e análise dos dados registrados no coletivo da escola. No conjunto e apresentados em formato inédito, esses dados, possibilitam combinações diversas, que revelam nuances pouco exploradas e o refinamento de interpretações de achados - o que pode evidenciar novas relações, a consolidação das práticas pedagógicas e sugerir novos rumos às políticas curriculares.

Destaca-se, também, a relação entre os dados registrados sobre transparência, publicização e visibilidade das práticas que se desenvolvem no cotidiano escolar e os pais, responsáveis e a comunidade via redes, acessíveis nas residências dos alunos, possibilitando a aproximação contínua das famílias com a trajetória do estudante e da escola.

Para se visualizar a complexidade e o empenho da rede de professores, coordenadores, conselhos de classe e diretores, constate-se que são gerados mais de 350.000 boletins eletrônicos (ou impressos) por bimestre, em 2013, numa rede que, um ano antes, gerava-os a partir de diários de classe e com relatórios de notas e faltas, com sucintas observações analíticas de trajetória e desempenho do alunado. A partir de 2014, todos os boletins puderam estar disponíveis online nas casas ou nos computadores em rede, a partir da matrícula/senha do aluno.

Em 2017, foi consolidado o Currículo da Cidade de São Paulo, criado de forma compartilhada "a partir dos conhecimentos produzidos e das práticas realizadas pelas professoras e professores da Rede Municipal de Ensino" (SME, 2020a). O documento trouxe a experiência paulistana em relação à reflexão da rede sobre a Base Nacional Comum Curricular (BNCC) com respeito ao que já havia sido construído pela própria rede.

Durante os anos que se seguiram à implantação do Currículo da Cidade, as escolas foram apreendendo tanto a operação, como o registro e a nova cultura de gestão pedagógica, construída a um só tempo por meio da refor- 
mulação curricular, da institucionalização do SGP e das reflexões sobre a prática docente e da comunidade escolar. Após sete anos, em 2020, foi lançado o "Novo SGP", superando os problemas e limitações identificados na versão inicial e trazendo novas funcionalidades (SÃO PAULO, 2020).

\section{A gestão das informações da educação}

O registro dos dados do cotidiano da escola pelos professores é armazenado e consolidado, ficando disponível para acesso e análise pelos professores e gestores escolares na forma de diferentes documentos, como relatórios, gráficos ou indicadores. Esses relatórios apresentam a trajetória dos alunos individualmente, bem como a visão do conjunto das diferentes turmas de uma ou mais séries, de uma escola ou de grupos de escolas, "... contribuindo assim, com ferramentas para a gestão dinâmica do processo de ensino e aprendizagem.” (SÃO PAULO, 2014b, p. 32).

O SGP prevê o registro sistemático feito pelos professores dos seguintes protocolos: o diagnóstico dos alunos;

1. planejamento;

2. projetos interdisciplinares desenvolvidos em colaboração;

3. planos de aula;

4. frequência;

5. atividades realizadas;

6. notas ou conceitos dos alunos;

7. anotações e diagnósticos sobre os alunos e suas trajetórias;

8. relatos da evolução dos alunos e turmas;

9. análise e propostas feitas pelos alunos de seu desempenho e do seu próximo bimestre;

10.orientações a alunos e famílias, dentre outras possibilidades.

Esses registros e sua recuperação podem ser realizados em computadores conectados à internet, sejam computadores de mesa ou dispositivos móveis.

Não apenas os professores registram, o SGP possui ambientes para apoio à realização e anotações do conseIho de classe, para registro de compromisso de estudos pelos alunos e outros espaços colaborativos.

Os agentes dos órgãos gestores centrais da Secretaria Municipal de Educação podem acessar os dados gerenciais compatibilizados por classes, escolas, regionais e disciplinas, ano a ano, o que permite uma visão de quadros históricos e das concentrações de dificuldades ou de facilidades. Para o acesso aos dados consolidados e para simulações, foi construído um painel digital (dashboard) que apresenta variadas visualizações e a síntese de indicadores relevantes para cada equipe.

A construção de indicadores é dinâmica e contínua, uma vez que a própria Rede as constrói. Para isso, a comunidade de educadores necessita de um período de apropriação dessa nova forma de olhar para a avaliação (avaliação para a aprendizagem), para conceber e desenhar novos indicadores em diferentes formatos que possam revelar relações inéditas entre os dados registrados. Este é um processo de aprendizagem, que relativiza a avaliação individual do aluno pelo professor, focalizando-a no contexto da avaliação das turmas de alunos pelo conjunto de professores e pelo conselho escolar. Um novo olhar se soma a esta dinâmica: a avaliação do próprio aluno sobre sua aprendizagem e sobre as avaliações dos professores e conselho.

Sintetizar, organizar, compatibilizar os dados comparáveis e indicadores da educação, em vez de reduzi-los, como muitas vezes sugere o senso comum, amplia e adensa o olhar às escolas em suas singularidades e em seu conjunto; desvela também particularidades e riquezas não visíveis, identificando suas qualidades, diagnosticando suas demandas e conferindo sentido às políticas públicas em prol da qualidade social da educação.

Pode-se verificar aqui a construção concreta do sentido da qualidade social de educação em três dimensões explícitas. De um lado, revela-se a qualidade social do direito à informação do planejamento proposto pelos professores da escola para toda a escola. Seus colegas, as coordenações, os pais e os alunos podem verificar sua proposta e acompanhar suas mudanças e o cumprimento delas. Outra variável que indica um compromisso social e público é a presença de documentação precisa sobre o desenvolvimento objetivo dos alunos, evidenciado pelo 
registro diário de atividades, conteúdos trabalhados e pela presença dos alunos. Por último, a prestação de contas regular e periódica dos resultados dos professores, dos alunos e da própria pertinência e adequação do currículo. Estes três destaques sobre a qualidade social do programa de gestão não esgotam as qualidades que são esperadas de sua implantação, assim como das que já foram notadas.

Francisco Soares, em entrevista à Revista Magistério 4, pontua: "Sonho que possamos, um dia, especificar os direitos de aprendizagem do aluno em termos tão claros que as pessoas não técnicas da área educacional possam entender." (SÃO PAULO, 2015, p. 10). Esta é a dimensão de transparência da qualidade social da educação: que se crie um mundo de comunicação entre a escola e a comunidade escolar (ou não escolar) no qual o universo da educação, embora específico e rigoroso, possa ser comunicado. Neste mesmo sentido continua Soares: "A existência de resultados (proclamados) permite tornar a pedagogia mais científica, gerenciar melhor os processos e verificar se os direitos dos alunos foram atendidos" (idem, p.7).

Com mais detalhes, estão a seguir descritas algumas funcionalidades do SGP dando passos na construção da qualidade social.

\section{Diagnóstico, planejamento, avaliação e o acompanhamento da trajetória dos alunos}

O SGP possui espaços para o registro da vida do aluno e da vida da escola, constituindo-se como uma memória que se constrói abrangendo desde o diagnóstico inicial da turma e dos alunos até os mapas das trajetórias ao final de cada ano letivo. A cartografia desses mapas é dinâmica e demanda o envolvimento sistemático dos agentes da escola no registro dos trajetos, no destaque dos pontos de passagem (waypoint) ou de destaque, nos ajustes de rota e no detalhamento dos relatos dos que realizaram as caminhadas.

Como ponto de partida, o SGP sugere o relato do diagnóstico dos educandos pelos professores e gestores, seja recuperando sua trajetória nos anos anteriores, seja por meio da investigação contínua e multidimensional. Salienta Selma Rocha em sua fala no Seminário Interno Mais Educação São Paulo e sintetizado no documento Programa Mais Educação São Paulo - Subsídios para Implantação (SÃO PAULO, 2014): Não é possível estabelecer mediação sem saber com quem se está falando... Para tanto é necessário estabelecer na Unidade Educacional um ambiente de investigação cognitiva que se debruce sobre a questão: Como o educando - criança jovem ou adulto pensa, se representa, se comunica, faz relações e abstrai? (p. 11). Assim, evitando focar no que "falta" ao educando e enxergá-lo como um "vir a ser", faz-se necessário conhecê-lo e compreendê-lo como ele é, sua experiência social e familiar, para além do levantamento de seu perfil socioeconômico.

Iniciada a trajetória, em face ao diagnóstico inicial dos educandos, os educadores encontram espaços para a realização do planejamento anual, semestral, bimestral - um espaço colaborativo (wiki) para o registro dos projetos interdisciplinares para cada ciclo de aprendizagem. Um ambiente específico é dedicado ao plano de aula individual ou coletivo, nos casos de docência compartilhada. Para a composição dos planejamentos, ficam disponíveis documentos organizadores do currículo, como referenciais nacionais, municipais e os construídos pela própria escola, como o seu Projeto político-pedagógico (PPP).

O registro não se configura propriamente uma inovação, mas o registro compartilhado e disponível em tempo real, ano a ano, de todos os alunos; os planejamentos anuais; os planos de aula de cada professor; e o desenvolvimento das ações para atingimento dos planos e seus ajustes se constituem em informações vitais para a construção do PPP e da proposição de ações, favorecendo:

- A potencialização da criação de novas culturas educacionais e do processo de construção do conhecimento.

- A contribuição com a construção de parâmetros avaliativos para reorientar o planejamento de práticas pedagógicas, de ações coletivas da escola e, inclusive, de um novo olhar sobre o PPP da escola.

- A reflexão do educador sobre suas práticas, com maior articulação entre o planejamento anual e o que se faz no cotidiano. (SÃO PAULO, 2014b, p.11). 
O registro acompanha o cotidiano, resguardando e resgatando a memória da escola, com possibilidade de acesso por todos seus agentes. "A unidade educacional é um espaço de criação e recriação da cultura. Não é só da promoção da aprendizagem... Um conjunto de áreas pode dialogar com a experiência educativa” (SÃO PAULO, 2014c, p.13).

\section{A gestão do conselho de classe}

O conselho de classe, que reúne as equipes gestora e docente e é uma das principais instâncias do processo de ensino e aprendizagem das escolas paulistanas, constitui-se em "...momentos de tomada de decisão coletiva quanto ao processo contínuo de avaliação, recuperação, compensação de ausências e promoção dos educandos" (2013c, p.1).

Ao final de cada bimestre, os registros são apreciados e debatidos pelos membros do conselho de classe. Os conceitos ou notas sugeridas pelos docentes são retificados ou ratificados na reunião, tomando como base a própria história da unidade escolar que também realiza no coletivo as anotações sobre o desenvolvimento e aprendizagens e provê orientações aos alunos e às famílias.

Os debates provenientes do conselho de classe devem estar voltados à reflexão crítica do trabalho escolar e de seu projeto. É neste momento em que se verificam não apenas orientações de correção de rumos e das dificuldades, mas o surgimento de propostas de ação. Os debates são, em seu melhor entendimento, o momento privilegiado do coletivo da escola para aprender a avaliar para a aprendizagem com qualidade social.

Registrar esse complexo processo num Sistema de Gestão Pedagógica é um desafio em construção, uma vez que a dinâmica dos conselhos de classe também é uma construção. O que se aprende com o uso do SGP no processo é dar visibilidade às individualidades, às singularidades e é o momento para ressignificar o espaço coletivo de avaliação, e inverter algumas práticas já presenciadas em escolas que, inadvertidamente, focam na avaliação classificatória e priorizam o debate da situação do aluno "que não vai bem".

\section{Espaços autorais para os alunos}

Não apenas os professores registram o processo de aprendizagem dos alunos, mas o SGP prevê a construção de espaços autorais institucionalizados que conferem voz aos alunos e oportunizam a publicação da reflexão sobre sua própria trajetória de aprendizagem. Esse espaço é denominado "compromisso de estudos". Nele o aluno acessa o boletim, pode ponderar sua participação e manifestar sua análise em face aos resultados. Ele pode reagir às observações dos professores sobre sua aprendizagem e às orientações do conjunto de professores no conselho de classe. Para tanto, são feitas ao aluno duas provocações, que buscam captar sua reflexão e que ficam visíveis aos professores e aos pais, no boletim: "O que tenho feito" e "O que pretendo fazer?".

A análise dos registros nesses espaços revela que, além de refletirem sobre sua trajetória de aprendizagem, os alunos por vezes discordam da avaliação dos professores, justificam-se ou planejam suas ações. Essa é a essência de colocar o educando como sujeito das ações.

Segundo Silva, "A criação de políticas públicas que reconheçam e confiram voz aos alunos ao propiciar espaços autorais no currículo de forma institucionalizada traz um panorama instigante sobre como o aluno analisa sua trajetória e sua responsabilização pela aprendizagem." (2014, p.17). Essa é a essência de colocar o educando como sujeito das ações. E os professores, o que aprendem com isso? Aprendem que, ao conferir voz e autoria aos alunos, as respostas são reflexões maduras sobre a própria aprendizagem e a corresponsabilização pela construção de sua trajetória.

\section{Boletim online e transparência}

O acesso aos boletins bimensais pelos pais/responsáveis por meio da internet, possibilitado pelo SGP, é um 
dos processos em prol da transparência das ações que se desenvolvem no cotidiano.

Segundo as reflexões dos grupos de educadores que subsidiam a implantação da avaliação para a aprendizagem, o processo permite: o acompanhamento mais individualizado dos alunos e a possibilidade do registro qualificado da vida escolar ao longo dos anos de escolarização. A maior participação das famílias no que se refere ao acompanhamento da trajetória escolar dos alunos. A visibilidade e transparência conferida ao trabalho da escola. (SÃO PAULO, 2014b, p. 22)

Contrariando as expectativas iniciais, a consulta pelas famílias dos boletins online não provoca a redução da presença ou a eliminação da reunião de pais, mas ressignifica e qualifica esses encontros e provoca a interação escola-família. E assim, vai se tecendo uma nova cultura de gestão pedagógica nas escolas.

\section{Desafios}

Obstáculos de naturezas diversas também acompanharam e continuam desafiando o processo de implantação do SGP, mesmo em sua mais recente versão. Por conta da complexidade características da Rede, a SME desenvolveu o caderno "Subsídios para Implantação da Avaliação para a Aprendizagem e SGP" (SÃO PAULO, 2014b).

Um dos pontos nevrálgicos deste processo foi a migração, no início de 2014, do serviço de internet de uma operadora para outra com a instalação de redes de fibra óptica, demandando o cabeamento e instalação de postes e caixas em todo o município. Essa operação se deparou com questões inusitadas, como furto de cabos, vandalização de caixas, necessidade de negociação com líderes de comunidades para a permissão da entrada do material, entre outras, que provocavam a queda massiva de internet por vários dias. Para contornar tais questões, foi criado um comitê de monitoramento diário, além de ações para a integração com a comunidade e inter-secretarias.

Outras dificuldades encontradas estão relacionadas à disseminação da cultura digital nas escolas e são enfrentadas com programas de formação nas Diretorias de Educação.

Segundo o relato e a reflexão dos grupos de trabalho que originaram o documento Subsídios para Implantação da Avaliação para a Aprendizagem e SGP (São Paulo, 2014b), os desafios pedagógicos apontados se relacionaram, em grande parte, à criação de referências para o planejamento e a avaliação alinhadas ao currículo. A pouca familiaridade da comunidade com processos contínuos de planejamento, avaliação e registro foram pontuados. Foram identificados, ainda, "dificuldades na exposição de seus registros, por parte dos educadores, antes realizados em uma esfera mais individual" (SÃO PAULO, 2014b, p. 26) como desafios de ordem pessoal.

O pouco uso de tecnologias pelos professores também foi identificado e alvo de grandes debates, de seminários e até mesmo de sugestões de mudanças no papel dos Professores Orientadores de Informática Educativa (POIE), presentes na rede desde 1995 como responsáveis pelo uso pedagógico das tecnologias nas escolas, abrindo espaços para a apropriação das tecnologias para a educação pelos professores (não exclusivo do SGP, mas para a educação) e a configuração do papel dos POIE como gestores de projetos.

A concepção e implantação de um sistema de gestão pedagógica não deixaram de provocar estranheza na Rede Municipal de Educação, que embora buscasse desmistificar o conceito de tecnologia enquanto ferramenta de controle e não associado à frequência do professor, provocou desconforto e questionamentos no corpo docente e gestor, tendo sido, inclusive, uma das pautas de greve e reivindicações e desencadeando muitos debates produtivos.

\section{O novo SGP}

Lançado em 2020, o Novo SGP continua como um organismo em desenvolvimento. Apresenta novas funcionalidades conforme anunciado no Guia do Novo SGP (SME, 2020b). A estrutura da nova versão está "pautada nos princípios e objetivos de aprendizagem e desenvolvimento do Currículo da Cidade" (SME, 2020b, p.3) e articulada 
com os Objetivos do Desenvolvimento Sustentável ${ }^{4}$. O novo SGP está, também, conectado à Plataforma do Currículo da Cidade de São Paulo ${ }^{5}$, alimentada com práticas, sequências didáticas e conexões possíveis das e entre as disciplinas.

\section{CONSIDERAÇÕES E REFLEXÕES}

O diálogo entre tecnologias, gestão democrática e avaliação para a qualidade social da educação aponta para a integração das tecnologias ao currículo e indica caminhos para a apropriação no fazer pedagógico, mormente quando se trata de traçar políticas públicas de prestação de conta de resultados.

Na maioria das ofertas de sistemas digitais para gestão escolar evidencia-se o caráter de controle, como o de saber se os alunos estão frequentando as aulas, quando os pais devem ser chamados à escola, ou como controlar se os professores estão cumprindo a programação. No SGP, em função da elaboração das funcionalidades serem realizadas com e por professores e coordenadores pedagógicos, enfatizou-se um processo rico de construção do planejamento que leva à reflexão sobre a qualidade das ações pedagógicas. O contexto de sua criação é o compromisso com um projeto de reforma curricular em fase inicial de implantação. Muitos limites surgiram durante a implementação do sistema. No entanto, depois de exposto, debatido e melhorado, uma vez que o processo de elaboração do Novo SGP foi e continua sendo uma construção colaborativa, esse sistema digital tem demonstrado a relevância de se considerar a gestão participativa como fundamento de um instrumento de gestão escolar.

A presença dos alunos não se cobra pelos registros de ausência, mas pela falta que ele faz na dinâmica da turma. As suas faltas não são um problema. As faltas manifestam que há problemas. Tais problemas não se resolvem pela simples denúncia das faltas, mas por sua análise pedagógica: "O que está havendo que você falta na aula de Física, mas não na de Língua Portuguesa?". Pode-se perguntar ao professor: "O que há com o aluno tal, que falta em suas aulas e sempre vai bem?" Ou perguntar ao aluno: "O que está acontecendo que no ano passado você não faltava e agora já tem oito faltas, em três meses?" Ou iniciar uma conversa com os pais: "O que podemos fazer juntos com seu filho para a melhoria de seus estudos?".

O registro de notas e faltas exige um tratamento pedagógico posterior refinado, analítico e propositivo. Tratamento para o qual os professores têm que ser formados conjuntamente com a equipe Supervisora e equipe Pedagógica da Escola.

A formação dos educadores para a análise e interpretação dos dados e de como orientar os alunos a partir deles é desafio ao qual a escola tem que se propor, embora inaugure uma lógica diferente de avaliar e planejar. As TDIC podem contribuir com a possibilidade de documentação, rápido acesso, cruzamento de dados e da visão sinótica de curvas históricas de evolução.

A análise da documentação da construção e uso do sistema de gestão pedagógica reafirma o potencial das TDIC como meio de estender os limites e as possibilidades da gestão educacional. Uma pergunta freireana pode resumir a questão: A quem serve a tecnologia? Quem a usa como instrumento de aperfeiçoamento de sua leitura do mundo? E para a leitura de si mesmo neste mundo? Se a resposta for "o aluno e seu processo de apropriação do mundo, no contexto do currículo e do conhecimento escolar", a gestão está no caminho acertado.

É possível realizar uma gestão pedagógica em prol da qualidade social da educação sem o uso de tecnologias? Certamente, entretanto é legítimo afirmar que as tecnologias em rede, o acesso em tempo real dos registros, a organização dos dados, a visão do conjunto da escola e das escolas ampliam sobremaneira a oportunidade da gestão pelo professor, pelo gestor, pelo aluno e familiares/responsáveis. Cabe ressaltar que não é um sistema qualquer, pronto e universal, mas construído pelos professores e para os professores, tratando das questões peda-

${ }^{4}$ As Nações Unidas definiram os Objetivos de Desenvolvimento Sustentável (ODS) como parte de uma nova agenda de desenvolvimento mundial. Foi lançada em setembro de 2015 durante a Cúpula de Desenvolvimento Sustentável, discutida na Assembleia Geral da ONU. Recuperado em 20 de agosto de 2020, de https://nacoesunidas.org/pos2015/

${ }^{5}$ Plataforma do Currículo Digital da Cidade de São Paulo. Recuperado em 20 de agosto de 2020, de https://curriculo.sme.prefeitura.sp.gov.br/ 
gógicas num primeiro plano, sem sugerir que a tecnologia obscureça o fazer da escola, mas que, ao contrário, dê luz aos seus fazeres.

Ao buscar responder às questões iniciais, a pesquisa nos documentos, portarias, guias, registros de reuniões e revistas da SME aponta que esse desenho é possível e que demanda o processo de construção colaborativa, com a participação ativa de todos os integrantes da rede, reflexões, acertos e erros, reconstruções para, a um só tempo, tomar nas mãos o currículo construído, o sistema de gestão pedagógica que interaja com o currículo, a construção de novas práticas de gestão e docência. Tal projeto é um apontamento na direção da construção de uma escola pública com uma educação de qualidade social.

\section{REFERÊNCIAS}

ALMEIDA, F. J. Paulo Freire. Folha explica 81. São Paulo: Publifolha. 2009.

Brasil. Ministério da Educação. Plano Nacional de Educação (2014-2024). 2014.

Casali, A. A qualidade social do currículo. São Paulo. Secretaria Municipal de Educação. Diretoria de Orientação Técnica. Programa Mais Educação São Paulo: Subsídios para Implantação. São Paulo: SME/DOT. 2014.

FREIRE, M. A paixão de conhecer o mundo. Rio de Janeiro: Paz e Terra. 1983.

OSTETTO, L. E. Registro na educação infantil: pesquisa e prática pedagógica. Campinas: Papirus. 2018.

SÃO PAULO. Secretaria Municipal de Educação. Mais educação São Paulo: programa de reorganização curricular e administrativa, ampliação e fortalecimento da Rede Municipal de Ensino de São Paulo. São Paulo: SME. 2013.

SÃO PAULO. Secretaria Municipal de Educação. Notas técnicas sobre o documento de referência do programa de reorganização curricular e administrativa, ampliação e fortalecimento da rede municipal de ensino de São Paulo. São Paulo: SME. 2013b.

SÃO PAULO. Secretaria Municipal de Educação. Regimento educacional das unidades da rede municipal de ensino.

Portaria 5941/13 - SME, de 15 de outubro de 2013. São Paulo: SME. 2013c.

SÃO PAULO. Secretaria Municipal de Educação. Programa mais educação São Paulo. Subsídios para implantação. São Paulo: SME. 2014.

SÃO PAULO. Secretaria Municipal de Educação. Programa Mais Educação São Paulo. Subsídios para implantação: avaliação para a aprendizagem e SGP. São Paulo: SME. 2014b.

SÃO PAULO. Secretaria Municipal de Educação. Revista Magistério (3). O aluno. São Paulo: SME. 2014c.

SÃO PAULO. Secretaria Municipal de Educação. Revista Magistério (4). Avaliação como Direito do Aluno. São Paulo: SME. 2015.

SÃO PAULO. Secretaria Municipal de Educação. Portal. Acesso em: 25 ago. 2020, Disponível em:<https://educacao.sme.prefeitura.sp.gov.br/>.

SÃO PAULO. Secretaria Municipal de Educação. Novo SGP: Manual do Novo Sistema de Gestão Pedagógica. 
Acesso em: 25 ago. 2020, Disponível em: <https://novosgp.sme.prefeitura.sp.gov.br/login>

SILVA, M. A. Qualidade social da educação pública: algumas aproximações. Caderno Cedes, v. 29, n. 78, p. 216226, 2009.

SILVA, M. G. M. De navegadores a autores: a construção do currículo no mundo digital. Anais do XV ENDIPE. Encontro nacional de didática e prática de ensino. Belo Horizonte: UFMG, p. 1-20. 2011.

. A voz do aluno, em alto e bom som. In: São Paulo. Secretaria Municipal de Educação. Revista Magistério, n. 3, p. 2-12. O aluno. São Paulo: SME/DOT. 2014.

SOARES, F. Currículo e avaliação: diálogo necessário. In: SÃO PAULO. Secretaria Municipal de Educação. Revista Magistério, n. 4, p. 4-14. São Paulo: DOT. 2014.

VIEIRA PINTO, A. O conceito de tecnologia. Rio de Janeiro: Contraponto, 2005.

ZUIN, A. A. S. Plano nacional de educação e as tecnologias da informação e comunicação. Educação e sociedade, n. 31, p. 961-980. Campinas: Cedes. 2010. 